\title{
International Journal of Education and Management Engineering
}

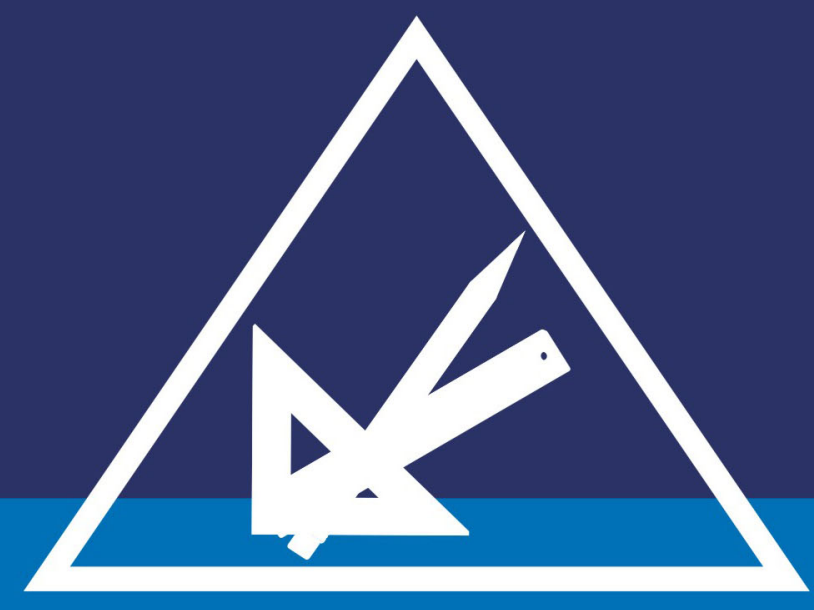

IJEME KgI.5

Http:// www.mecs-press .org

Vol. 5 No. 3 July 2015 


\section{International Journal of Education and Management Engineering (IJEME)}

ISSN: 2305-3623(Print), ISSN: 2305-8463(Online)

Volume 5, Number 3, July 2015

\section{Contents}

\section{REGULAR PAPERS}

Change Impact Identification in Object-Oriented System: Dependence Graph Approach

Abdi Mustapha Kamel, Dinedane Mohammed Zoheir

Implementation of Non-Repudiation Services in Digital Video Generation \& Distribution on 9 Android Devices

Pooja Gupta, Ankita Lavania, Madhuri Agarwal, Vrijendra Singh

Architecture Design Selection Scheme for Usability Quality Attribute 